Disclosure of Interest: None declared

DOI: 10.1136/annrheumdis-2017-eular.1611

\section{AB1111 A PROSPECTIVE COHORT STUDY MEASURING COST-BENEFIT ANALYSIS OF THE OTAGO EXERCISE PROGRAMME IN COMMUNITY DWELLING ADULTS WITH RHEUMATOID ARTHRITIS}

S. Abdulrazaq ${ }^{1}$, T. O'Neill ${ }^{2}$, E.K. Stanmore ${ }^{3}$, J. Oldham ${ }^{1}$, D. Skelton ${ }^{4}$, M. Pilling ${ }^{5}$, B. Gannon ${ }^{1}$, C. Toddd ${ }^{1}{ }^{1}$ School of Nursing, Midwifery and Social Work and MAHSC; ${ }^{2}$ School of Medical Sciences; ${ }^{3}$ School of Nursing, University of Manchester, Manchester; ${ }^{4}$ University of Glasgow, Glasgow; ${ }^{5}$ University of Manchester, Manchester, United Kingdom

Background: Falls are one of the major health problems in adults with Rheumatoid Arthritis (RA). Interventions, such as the Otago Exercise Programme (OEP), can reduce falls in community dwelling adults by up to $35 \%$. The cost-benefits of such a programme in adults with RA have not been studied

Objectives: To determine healthcare cost of falls in adults with RA, and estimate whether it may be cost efficient to roll out the OEP to improve function and prevent falls in adults living with RA.

Methods: Patients with Rheumatoid Arthritis aged $\geq 18$ years were recruited from four rheumatology clinics across the Northwest of England. Participants were followed up for 1 year with monthly fall calendars, telephone calls and self-report questionnaires. Estimated medical cost of a fall-related injury incurred per-person were calculated and compared with OEP implemention costs to establish potential economic benefits.

Results: 535 patients were recruited and 598 falls were reported by 195 patients. Cumulative medical costs resulting from all injury leading to hospital services is $£ 374,354$ (US\$540,485). Average estimated cost per fall is $£ 1120$ (US\$1617). Estimated cost of implementing the OEP for 535 people is $£ 116,479$ (US\$168,504) or $£ 217.72$ (US\$314.34) per-person. Based on effectiveness of the OEP it can be estimated that out of the 598 falls, 209 falls would be prevented. This suggests that $£ 234,583$ (US $\$ 338,116$ ) savings could be made, a net benefit of $£ 118,104$ (US $\$ 170,623)$.

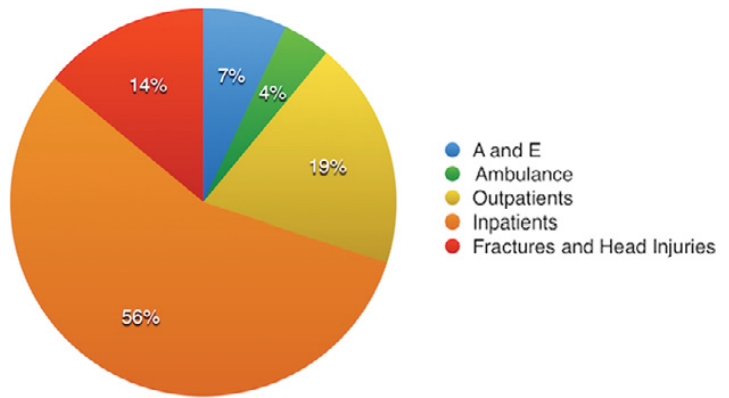

Figure 2. Chart showing spread of cost in health care costs

Conclusions: Implementation of the OEP programme for patients with RA has potentially significant economic benefits and should be considered for patients with the disease.

\section{References:}

[1] Stanmore EK, Oldham J, Skelton DA, O'Neill T, Pilling M, Campbell AJ, et al. Fall incidence and outcomes of falls in a prospective study of adults with rheumatoid arthritis. Arthritis Care Res (Hoboken). 2013;65(5):737-44.

[2] Stanmore EK, Oldham J, Skelton DA, O'Neill T, Pilling M, Campbell AJ, et al. Risk factors for falls in adults with rheumatoid arthritis: a prospective study. Arthritis Care Res (Hoboken). 2013:65(8):1251-8.

[3] Hayashibara M, Hagino H, Katagiri H, Okano T, Okada J, Teshima R. Incidence and risk factors of falling in ambulatory patients with rheumatoid arthritis: a prospective 1-year study. Osteoporos Int. 2010;21(11):1825-33.

[4] Gillespie LD, Robertson MC, Gillespie WJ, Sherrington C, Gates S, Clemson $\mathrm{LM}$, et al. Interventions for preventing falls in older people living in the community. Cochrane Database Syst Rev. 2012;9:CD007146.

[5] Gardner MM, Robertson MC, Campbell AJ. Exercise in preventing falls and fall related injuries in older people: a review of randomised controlled trials. British Journal of Sports Medicine. 2000;34(1):7-17.

[6] Robertson MC, Campbell AJ, Gardner MM, Devlin N. Preventing injuries in older people by preventing falls: a meta-analysis of individual-level data. J Am Geriatr Soc. 2002;50(5):905-11.

Acknowledgements: Special thanks to all the participants involved in the research and also the nursing staff who supported the data collection phase of the study at Manchester Academic Health Science Centre (MAHSC).

Disclosure of Interest: None declared

DOI: 10.1136/annrheumdis-2017-eular.1439

\section{AB1112 DATANETWORK RHEUMA 4.0 - REAL WORLD DATA FROM PRIVATE PRACTICE}

S. Kleinert ${ }^{1}$, F. Schuch ${ }^{1}$, S. Späthling-Mestekemper ${ }^{2}$, M. Feuchtenberger ${ }^{3}$, C. Kuhn ${ }^{4}$, M. Welcker ${ }^{5}$. ${ }^{1}$ Rheumatologie, Rheumatologische Schwerpunktpraxis, Erlangen; ${ }^{2}$ Rheumatologie, Rheumapraxis München-Pasing, München;

${ }^{3}$ Rheumatologie, Schwerpunktpraxis für Rheumatologie, Burghausen;

${ }^{4}$ Rheumatologie, Internistische Schwerpunktpraxis am Ludwigsplatz, Karlsruhe;

${ }^{5}$ Rheumatologie, MVZ für Rheumatologie Dr. Martin Welcker, Planegg, Germany

Background: The datanetwork Rheuma 4.0 (DNR_4.0) is a consortium of 5 internistic-rheumatologic specialized practices. Patient data that were collected routinely will be pooled pseudonymized (e.g. via RheumaDok) and will be made available to answer numerous healthcare- and scientific research questions.

Methods: The participating centres document the following data in specific rheumatologic data documentation systems (RheumaDok, Emil, DocuMed.rh). These data will be routed automatically to the data base of the DNR_4.0 via a prespecified interface and can be used for certain research areas:

Diagnosis (by rheumatologist $(R)$, anamnesis $(R)$, medication $(R)$, morning stiffness $(R$, patient $(P))$, scores like RADAI $(R, P)$, DAS28 (R), BASDAI (P), BASFI $(P)$, quality of life $(R, P)$. Also prespecified laboratory measures $(R)$ like ESR, CRP etc. can be collected automatically.

Patient reported Outcomes (PROs) that were entered via mobile applications like RheumaLive and AxSpALive can be collected in certain intervalls and be sent encrypted into the medical office data base.

The data entered by patients will be screened by the rheumatologist or nurse and will be stored in the underlying data base. Clinical data that are collected during regular F2F-appointments will be stored together with the PROs according to a specific period of time.

Results: The datanetwork Rheuma 4.0 (DNR_4.0) is an association of 5 internistic-rheumatologic specialized practices.

By the automated documentation of PROs (patient) and medical measures (rheumatologist) in an underlying data base, scientific and health care real worl data can be collected without extra workload or time requirements. These data are specific and different from data collected by other centres. In principal, the extension of the group to increase the number of participating centres is easily possible because the interface is an "open system". This allows to build an automised collecting, big and representative data base.

Now pooled data sets of 18.000 patients are available in the data base. In a first step, quality and the completeness of the existing data sets will be evaluated and the daily documentation routines will be described. Anonymised statistical analysis of the pooled data sets of the rheumatologic centres will allow to gain knowledge in respect to health care research of the own working group and external interested parties like research groups, sick funds, insurance companies and companies.

Conclusions: The german biologic registry Rabbit and the "Core documentation" data base deliver valid data about the safety and efficacy of rheumatologic medication. The datanetwork Rheuma 4.0 will make a valuable contribution especially in conjunction with apps of patient's self management like RheumaLive and AxSpALive - to health care research, therapeutic strategies and clinical questions from daily practice.

Acknowledgements: RheumaLive and AxSpALive werde developed by Starhealth $\mathrm{GmbH}$ on behalf of UCB Pharma $\mathrm{GmbH}$.

Disclosure of Interest: S. Kleinert Speakers bureau: UCB, F. Schuch Speakers bureau: UCB, S. Späthling-Mestekemper Speakers bureau: UCB, M. Feuchtenberger Speakers bureau: UCB, C. Kuhn: None declared, M. Welcker Speakers bureau: UCB

DOI: 10.1136/annrheumdis-2017-eular.5674

\section{AB1113 PATIENT PARTICIPATION IS CRUCIAL WHEN INTRODUCING NEW DEVICE TECHNOLOGIES IN THE MANAGEMENT OF CHRONIC ARTHRITIS: APPLYING THE PARKER MODEL, A QUALITATIVE 3-STEP APPROACH}

T.S. Jørgensen ${ }^{1}$, L. Klokker ${ }^{1}$, M. Skougaard ${ }^{1}$, H. Asmussen ${ }^{2,3}$, A. Lee ${ }^{4}$, I. Mountian ${ }^{5}$, H. Gudbergsen ${ }^{1}$, L.E. Kristensen ${ }^{1} .{ }^{1}$ The Parker Institute, Copenhagen University Hospital, Bispebjerg and Frederiksberg, Copenhagen; ${ }^{2}$ Communication IKH, Roskilde University, Roskilde; ${ }^{3}$ NATiON, Copenhagen; ${ }^{4}$ University of Southern Denmark, Odense, Denmark; ${ }^{5}$ UCB Pharma, Brussels, Belgium

Background: Patients' participation in design, development, and implementation of new device technologies is essential to ensure added value in patients' disease management.

Objectives: To explore the applicability and relevance of ava ${ }^{\circledR}$, an electromechanical device (e-Device), as an alternative method for subcutaneous administration of certolizumab pegol.

Methods: The Parker Model is an innovative 3-step qualitative research approach, which combined concept mapping (CM), participatory design (PD), and stakeholder evaluation (SE) to evaluate the e-Device (Figure). CM was applied through workshops, with the participation of patients, using a structured group process focusing on relevant themes to identify issues and concerns with the e-Device. Patients used this information in a series of iterative PD sessions; patients participated in 3 interactive sessions to create a personal e-Device prototype in 